\title{
Characterisation of Diffuse and Local Necking of Aluminium Alloy Sheets Using DIC Technique
}

\author{
Sz. Szalai ${ }^{1}$, D. Harangozó ${ }^{2}$, I. Czinege ${ }^{3}$ \\ ${ }^{1}$ Széchenyi István University, Department of Vehicle Manufacturing \\ Egyetem tér 1, H-9026 Győr, Hungary \\ e-mail: szalaisz@sze.hu \\ ${ }^{2,3}$ Széchenyi István University, Department of Materials Science and \\ Technology \\ Egyetem tér 1, H-9026 Győr, Hungary \\ e-mail: harangozo.dora@sze.hu, czinege@sze.hu
}

Abstract: This paper introduces a new method for the characterisation of the boundary of diffuse and local necking based on DIC measurements during tensile tests. A series of images illustrate the extension of diffuse necking and show the occurrence of local necking as well. The evaluation of strain distribution gives the exact description of processes using both time dependent and non-dependent methods.

Keywords: diffuse necking; local necking; tensile test; DIC measurement

\section{Introduction}

In a uniaxial tension test of aluminium sheets plastic instability and flow localization will occur just after the maximum load and the diffuse necking starts. After the onset of diffuse necking, the deformation continues under the falling load in the form of localized necking, which ultimately leads to ductile fracture.

The necking process was first described by Considère in 1885. According to his well-known criterion, the onset of necking occurs when the hardening rate equals to 
the true stress, just when the load reaches its maximum. From that follows that the first derivative of stress by strain equals to the stress:

$$
\frac{d \sigma_{1}}{d \varepsilon_{1}}=\sigma_{1}
$$

Diffuse necking starts from this point and a concentrated strain appears in a specific area of the specimen. The length of this area approximately equals its width. As the deformation continues, local necking occurs which can be characterised by a thin shear band accompanied by a significant decrease in thickness. The onset of local necking can be derived from another instability criterion as equation (2) shows [1].

$$
\frac{d \sigma_{1}}{d \varepsilon_{1}}=\frac{\sigma_{1}}{2}
$$

Considering the flow stress curve based on the Hollomon-Ludwik approach $\sigma=K \varepsilon^{\mathrm{n}}$ the onset of diffuse and local necking can be expressed by the n-value using equations (1) and (2). The hardening exponent (n) is defined by the uniform elongation $\left(A_{g} \%\right)$ with formula $n=\ln \left(1+A_{g} / 100\right)$. The location of diffuse instability according to Hill [2] and other authors $[3,4]$ is $\varepsilon_{D}=n$. Similarly, according to equation (2) the true uniaxial strain in tensile direction is $\varepsilon_{\mathrm{L}}=2 \mathrm{n}$ at the beginning of local necking. The above-mentioned theories were developed originally for mild steels but the $\varepsilon_{D}=n$ equation is valid for other materials as well $[5,6]$.

A good summary and further development of necking theory published by Ramaekers [7] with the following basic points:

- Local necking is related to load instability, $\mathrm{dF}=0$.

- It only occurs in a plane strain situation, intensive local thinning before fracture can be characterized by longitudinal and thickness strains.

- During the necking process there is a jump in the strain path from 3 axis to 2 axis strain state.

Taking these points into consideration diffuse and local necking criteria can also be used for evaluating the forming limit diagram (FLD) from Nakazima test results [7].

Newly developed Digital Image Correlation (DIC) techniques are useful tools for the visualization of necking processes, since local deformations of test specimens can be directly observed and strains can be evaluated. Recent publications show that both the PLC bands and post-necking strains can be identified and characterised. Digital image observations are frequently connected to FEM analyses. Coppieters et al [8] introduces an analysis of a model sheet simulating diffuse necking. Similarly, 
Kim et al [9] and Tardif et al [10] show DIC images both for diffuse and local necking.

A good comparison of AA5052-O aluminium alloy and DP980 steel can be found in Nguyen et al [11], where DIC images are associated with true strain distribution along the specimen axis. Here it was stated that the localization tendency and localized width of AL5052-O sheet are more significant compared to DP980 sheet. Portlevin-LeChatelier (PLC) bands and intensive shear bands are investigated in Kang et al [12] using AlMg3 samples.

The authors assume that PLC bands play an important role in the development of shear bands before fracture. Because of the very narrow shear band, damage occurs in terms of void nucleation and growth very late in the fracture process, and does not appear to significantly affect tensile ductility. The same observation can be found in Halim et al [13]. However, this latter publication includes that after the onset of local necking, the average strain does not increase in the other parts of the specimen, total strain is concentrated only in the shear band.

The above-mentioned examples are mainly related to tensile tests. Similar necking occurs during Nakazima tests. The main problem of the evaluation of Nakazima tests is how to find the onset of local necking. A possible solution is offered by the ISO 12004-2-2009 standard, where the determination of local necking is derived offline from the strain distribution before the fracture. This method is called timeindependent evaluation. However, there are time-dependent solutions as well, for example Hora et al [14] Merklein et al [15] and Friebe et al [16]. In time-dependent cases a series of strain distributions as the function of time are used for evaluation. Usually time derivatives of longitudinal or thickness strains are applied to mark the onset of local necking and to evaluate the value of minor and major strains.

\section{Material and methods}

The sheet studied here was AlMg3 (AA5754_H22) alloy with a thickness of 2.5 $\mathrm{mm}$ and a chemical composition of $3.41 \mathrm{wt} \% \mathrm{Mg}, 0.18 \mathrm{wt} \% \mathrm{Mn}, 0.17 \mathrm{wt} \% \mathrm{Si}, 0.23$ wt\% Fe. The width of the tensile specimens was $20 \mathrm{~mm}$, the gauge length was 80 $\mathrm{mm}$ and they were cut parallel, 45 degrees and perpendicular to the rolling direction. The tensile tests were carried out with an Instron 5582 machine with strain rate of $2 \cdot 10^{-3} 1 / \mathrm{s}$. Local strains were measured during the tensile test with the GOMARAMIS ${ }^{\circledR}$ hardware-software system and using the random pattern which has been applied to the specimens previously. Local strains have been determined with GOMCorrelate ${ }^{\circledR}$ software. The diagrams representing the elongation-stress, time-load values and local strains of the specimen were derived from images recorded during the test. GOM-Correlate ${ }^{\circledR}$ software is suitable for determining a wide range of local 
strains. In addition to axial, transverse and thickness strains it is also possible to obtain the equivalent (Mises) strain and stress. The strains presented in this study are all defined as equivalent (Mises) strains in percent (\%) except for the engineering strains $\mathrm{A}_{\mathrm{g}}$ and $\mathrm{A}_{80}$.

\section{Results}

According to the results of the tensile tests and the digitally recorded time parameter, the information based on images belonging to the elongation can be used to study the onset of diffuse and local necking. Firstly, the material in question was analysed whether it follows equations (1) and (2). To verify the correctness of the formula $\varepsilon_{\mathrm{D}}=\mathrm{n}$ and to determine the initiation of diffuse necking, it should be considered which value of the strain hardening exponent is applied to the equation. Engineering strains between $4-6 \%, 10-15 \%$ or $2-\left(A_{g}-1\right) \%$ are considered decisive according to the relevant standard.

Ramaekers [7] also refers to the alteration (initially increasing, then decreasing tendency) of the strain hardening exponent as the function of strain. Figure 1 shows the relation determined from the flow stress curve of a specimen cut parallel to the rolling direction. The horizontal line represents $n=0.211$ specified by the HollomonLudwik approach, the blue curve shows the values of $n$ numerically calculated from the model of Voce $\left(\mathrm{k}_{\mathrm{f}}=\mathrm{k}_{\mathrm{f} 0}+\left(\mathrm{k}_{\mathrm{f} 1}+\theta_{1} \cdot \varepsilon\right)\left(1-\exp \left(\theta_{0} \cdot \varepsilon / \mathrm{k}_{\mathrm{f} 1}\right)\right)\right.$ fitted on the flow stress curve, while the triangle indicates the $n$ value measured at the limit of uniform extension from $A_{g}$.

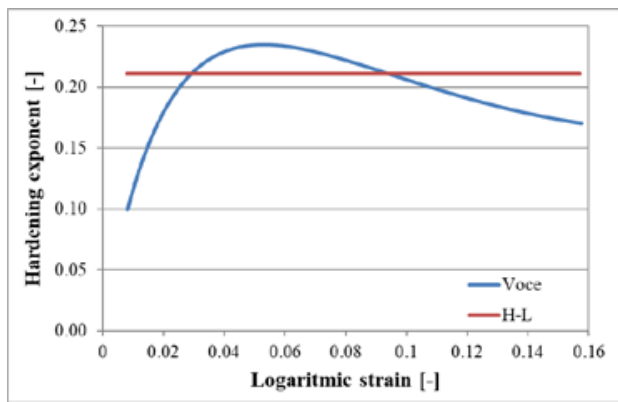

Figure 1. Evaluation of hardening exponent during uniform elongation

As can be seen, the falling section of the strain hardening exponent which is derived from the Voce model, can be approximated with a straight line corresponding to Ramaekers [7]. The whole curve is similar to the functions in Zhemchuzhnikova et al [5]. The location of $\varepsilon_{\mathrm{D}}$-n point reveals that the local value of the strain hardening exponent is approximately $10 \%$ higher than $\varepsilon_{\mathrm{D}}$, so $\varepsilon_{\mathrm{D}}=\mathrm{n}$ is not 
entirely true. At the same time, the strain hardening exponents derived from the Hollomon-Ludwik approach or interpreted between the previously mentioned boundaries (eg. 4-6\%), deviate much more from $\varepsilon_{\text {D }}$. Considering that the values of the logarithmic strains at fracture are about 0.2 , meeting equation $\varepsilon_{D}=2 n$ is unrealisable. Therefore, another method should be introduced to determine the onset of diffuse and local necking in case of tested aluminium-alloys. The results of DIC technique - to be presented below - can be suitable for this task.

Figure 2 shows a typical image of local strain map with main directions and a section of tensile test diagram of AA574_H22 sheet displaying the necking zone and the time interval to be tested.

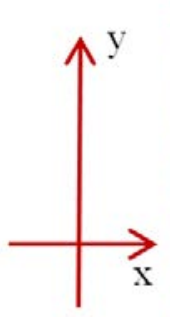

a)

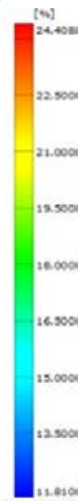

)

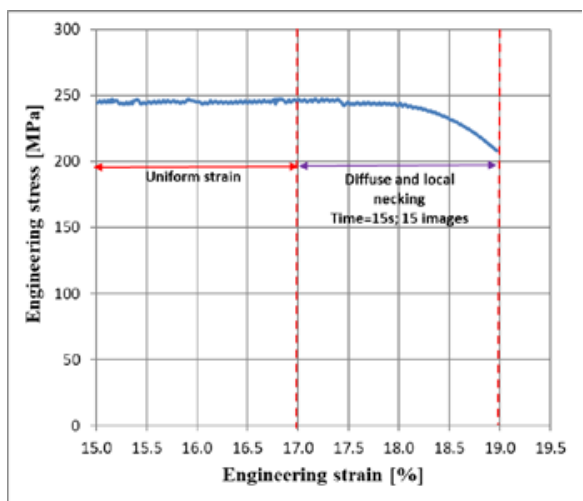

b)

Figure 2. Illustration of test specimen and diagram

a) local strains and coordinates b) tensile test diagram

Figure 3 shows the map of local strains sampled according to Figure 2 on specimens cut 0-45-90 degrees compared to the rolling direction. The graph under the three different images illustrates the maximum equivalent strain. The first eight pictures of this sequence clearly show the propagation of diffuse necking, while the maximum strain hardly increases in that zone. Therefore, the increment of average strain definitely takes place due to the expansion of the diffuse necking zone. The transition between diffuse and local necking appears in pictures 9-10 when the increase of the maximum strain also starts. The last five pictures clearly show intense localization and a rapid rise in the maximum strain with the appearance of the shear band.

It is interesting that in the recorded sequence of specimen H22_90 two diffuse necking zones appear first, then the lower one vanishes when local necking begins. In the recorded sequence of specimen $\mathrm{H} 22 \_0$ a special phenomenon can be observed 
in pictures $12-13$, namely a bidirectional intense strain band which aligns to the definite direction related to the fracture in picture 14 .
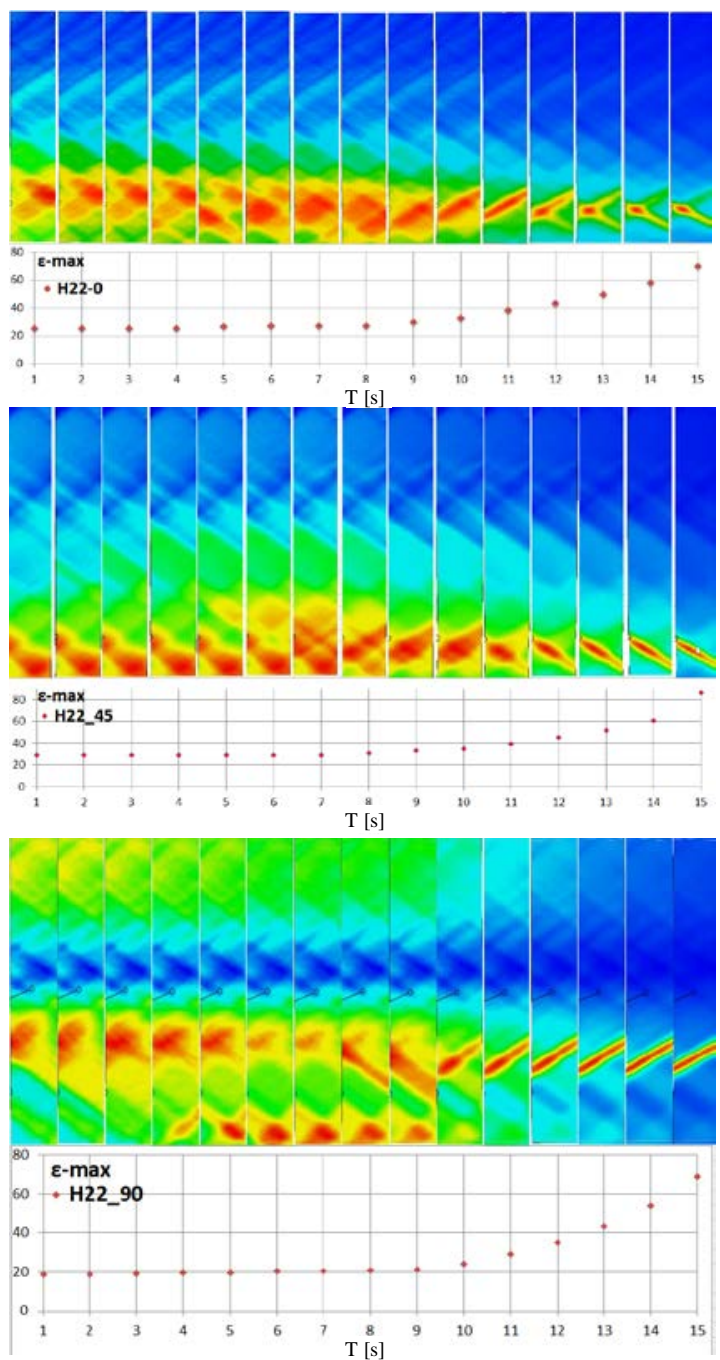

Figure 3. Time history of diffuse and local necking

Shear bands align at an angle of approximately $60^{\circ}$ to the axis of the specimen, which deviates from the theoretical $55^{\circ}$. In literature there are also examples of 
results approximating $60^{\circ}$. Observing the images together, it can be ascertained that the end of diffuse necking occurs in the ninth picture for all three specimens and local necking starts from the tenth picture. The graphs under the images show that the maximum strain can be a proper parameter to determine the boundary of the two types of necking.

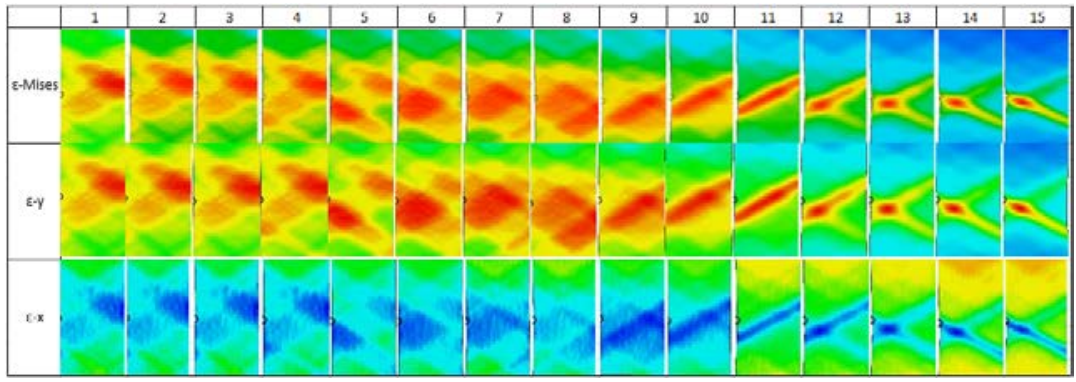

Figure 4. Comparison of Mises ( $\varepsilon$-Mises), longitudinal ( $\varepsilon-y)$ and thickness ( $\varepsilon-x)$ strains

The equivalent (Mises) strain, the longitudinal $(\varepsilon-y)$ and the thickness $(\varepsilon-x)$ strain can be seen in Figure 4. The Mises and the longitudinal strain distribution is virtually equal, the distribution of the thickness strain follows the shape of the intense deformation zone.

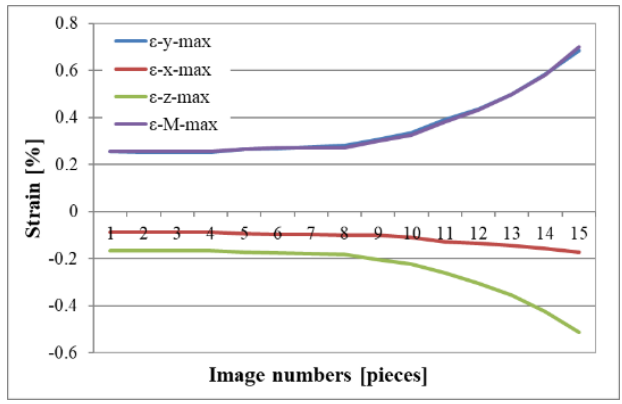

Figure 5. Principal strains and Mises strain vs time

Figure 5 shows strains as the function of time; where the axial strain approximately equals to the equivalent strain, similar to the images in Figure 3. The plot of the thickness $(\varepsilon-z)$ strain proves that the thickness reduction is significant in the shear zone which ultimately leads to fracture. 


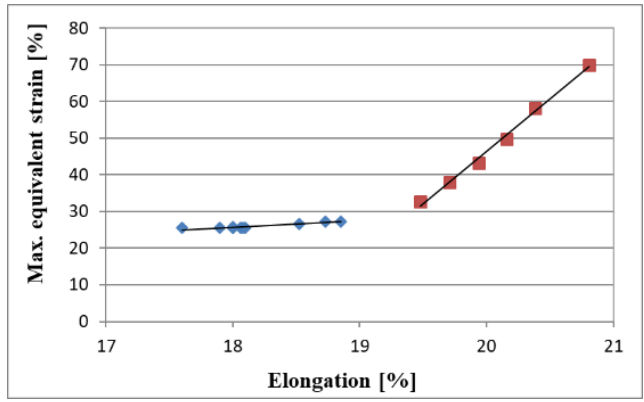

Figure 6. Calculation of the onset of local necking

Figure 6 shows the maximal equivalent (Mises) strain values as the function of the elongation in the area of diffuse and local necking. Eliminating the values of transition between the sections of characteristic diffuse and local necking, linear functions can be fitted for the points. The elongation belonging to the intersection can be specified from the equation of the lines, which is the boundary of diffuse and local necking. Table 1 contains the result of the evaluation completed in all three directions.

Table 1. Calculated and measured strains

\begin{tabular}{|c|c|c|c|}
\hline Angle to rolling direction & $0^{\circ}$ & $45^{\circ}$ & $90^{\circ}$ \\
\hline Uniform strain $\left(\mathrm{Ag}_{\mathrm{g}}[\%]\right)$ & 17.8 & 18.9 & 15.6 \\
\hline Onset of local necking strain, ( $\varepsilon_{L}[\%]$ ) & 19.36 & 21.44 & 16.35 \\
\hline Tensile strain ( $\left.\mathrm{A}_{80}[\%]\right)$ & 20.7 & 23.2 & 17.3 \\
\hline Maximum local strain, ( $\left.\varepsilon_{\operatorname{Mmax}}[\%]\right)$ & 70.0 & 86.7 & 69.2 \\
\hline Ratio of onset of local necking strain to uniform strain & 0.54 & 0.59 & 0.44 \\
\hline Image number at the end of diffuse necking & 9 & 9 & 9 \\
\hline Image number at the onset of local necking & 10 & 10 & 10 \\
\hline Mises strain at the onset of local necking, ( & 32 & 33 & 24 \\
\hline
\end{tabular}




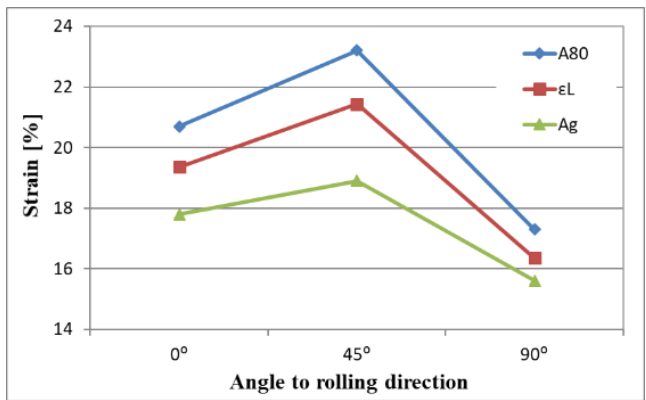

Figure 7. Onset of local necking strain between uniform and tensile strain

Typical measurement points are displayed in Figure 7. The boundary of the diffuse zone is positioned in the middle of the necking zone, similarly to the values in Table 1. The calculated point of intersection and the data from the images are in accordance, since the average strain assigned to the images matches well with the calculated strain. Considering the above points, the maximal strain determin at the onset of local necking $\left(\varepsilon_{\text {Lmax }}\right)$ as shown in the last row of Table 1 . The presented method is a time-dependent one, because the boundary of local necking and the major strain is defined based on the images in chronological order and the properties measured in the function of time.

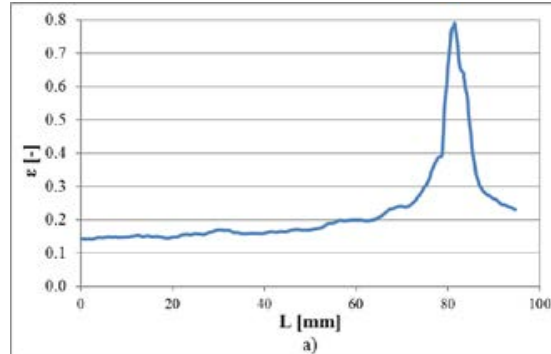

Figure 8. Strain distribution along specimen length

The information based on the images can be quantified by preparing sections parallel to the axis of the specimen and representing the local strains. Figure 8 . a) shows the strain of a $0^{\circ}$ specimen on the whole gauge length. In Figure 8. b) strain curves can be seen as the function of time from the area of intensive local necking. Apparently, at the end of diffuse necking, local strain in Im-8 starts to exceed the average strain, but its platform is almost horizontal. Curves of Im-9 and Im-10 show stronger increase, subsequently significant localization starts from image Im-11 
which is well illustrated together in the diagram. The same conclusion can be drawn from the images in Figure 3 as from Figure 8, namely local necking appears from Im-9. The value of local necking strain can be specified also from Figure 8 as the maximum of Im-9 curve.

The last image before the fracture (Im-15) provides the opportunity for timeindependent evaluation, similarly to the method suggested for the Nakazima-test according to ISO 12004-2-2009. Following the standard, left- and right-side fit windows should be designated to the length-major strain curve. The inner points of the windows are defined by the maximums of the second derivatives of the major strain curve, while the width is provided by an empirical formula. Fitting $f(L)=1 /\left(a L^{2}+b L+c\right)$ curve on the measured points, the value of the function at the place of fracture defines the major and minor strain at the start of local necking.

Figure 9 shows the original local strain function, the points of the fitting window and the inverse parabola fitted to the points. The maximum of the fitted function in case of $0^{\circ}$ specimen is 0,32 meaning to $32 \%$ strain, which equals to the value in the last row of Table 1. Similarly, the results of calculations accomplished in cases of $45^{\circ}$ and $90^{\circ}$ specimens approach the previously well-specified values. Consequently, both the time-dependent and time-independent methods provided nearly the same result.

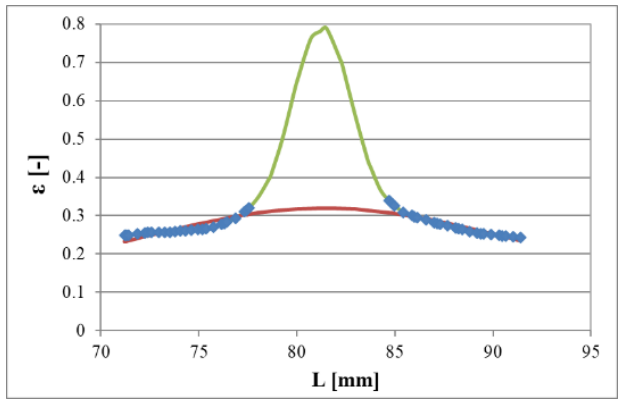

Figure 9. Determination of local necking according to ISO 12004-2-2009 standard

The quantified results of the presented longitudinal sections offer the opportunity to simplify the evaluation and to further characterisa local necking. Studying the shape of the curves, it is apparent that the results of the measurements can be approached with a four-parameter Gaussian function according to equation (3).

$$
f(L)=y_{0}+A \frac{\sqrt{2 / \pi}}{w} e^{-2\left(\frac{L-L_{c}}{w}\right)^{2}}
$$


In this formula, A stands for amplitude, $\mathrm{L}_{\mathrm{c}}$ is the centre of the function, $\mathrm{w}$ is the width measured at the points of inflexion and $y_{0}$ is the vertical offset parameter. Figure 10. a) shows the approaching functions and Figure 10. b) illustrates the first and second derivatives of the Gaussian function. The local coordinates of the maximum of the second derivative providing the inner points of the fitting window, are in a good accordance with the L-coordinates specified by the parabolic approach according to the ISO standard. The calculation of the second derivatives from the Gaussian function is more reliable than from the measured points with significant scattering.

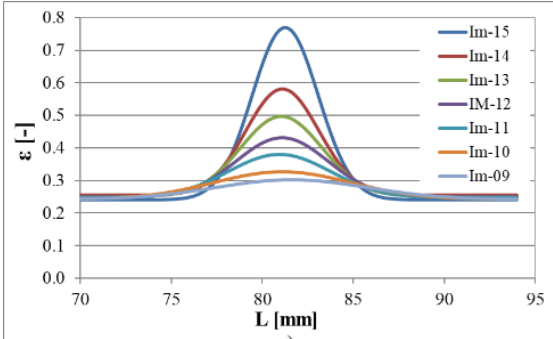

a)

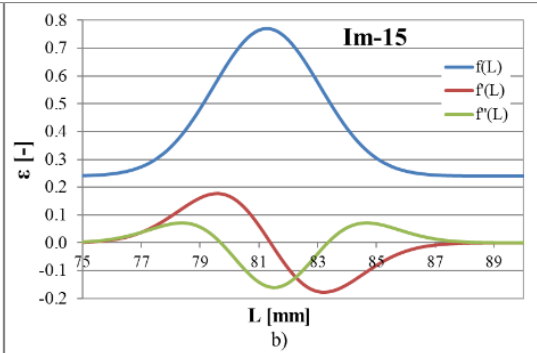

b)

Figure 10. Approximation of local strain with Gaussian function

a) strain distribution maps; b) derivatives of Gaussian function

The time-dependent change of the amplitude coefficients $\left(A=\varepsilon_{\max }\right)$ and the strain belonging to the point of inflexion $\left(\varepsilon_{1}\right)$ of the Gaussian functions also shows the increase of these strains. In contrast, the offset parameter $\left(\mathrm{y}_{\mathrm{o}}\right)$ is roughly constant, so the value of the diffuse strain does not change as the function of time, while a significant increase of local strains appear in the necking band. The distance of inflexion points $(\mathrm{w})$ decrease strongly in the function of time which is a peculiarity of localisation. All these functions can be seen in Figure 11.
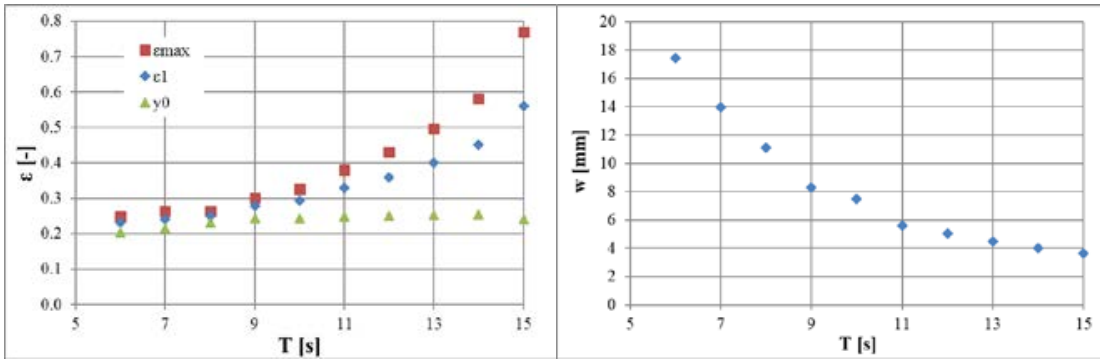

Figure 11. Change of Gaussian parameters versus time 


\section{Summary and conclusions}

The result of the research clearly certifies that the DIC technique is suitable for determining the boundary of diffuse and local necking and the value of the major and minor strain at the onset of local necking during tensile tests.

The boundary of diffuse and local necking can be determined by subjective estimation from the images, which can be precised by specifying the intersection of lines fitted for the points of average and maximal strain. This time-dependent method of evaluation provides reproducible results.

The evaluation can be executed according to ISO 12004-2-2009 from the values of the last strain curve before the fracture. This showed adequate agreement with the time-dependent method. Furthermore, based on the identified regularities, the major and minor strain can be estimated at the boundary of local necking through the results of the tensile tests.

The analysis of strain curves demonstrated that they can be approximated well with four parameter Gaussian functions whose coefficients characterise the necking zone, and they can also provid opportunity to precisely determine the second derivative of the strain.

\section{Acknowledgement}

The publishing of this paper was supported by "Research of digital image correlation technique and application for solution of vehicle developments" Nr. 20523-3/2018/FEKUTSTRAT and „EFOP-3.6.1-16-2016-00017 “Internationalization, initiatives to establish a new source of researchers and graduates, and development of knowledge and technological transfer as instruments of intelligent specializations at Széchenyi University”.

\section{References}

[1] J. G. Sevillano: Plastic anisotropy, formability and strain localisation. TECNUN, Materials Engineering.

URL http://www4.tecnun.es/asignaturas/estcompmec/documentos/thinsheets.pdf

[2] R. Hill: On the discontinuous plastic states, with a special reference to localized necking in thin sheets. Journal of the Mechanics and Phisics of Solids 1 (1) (1952) pp. 153-161.

doi: https://doi.org/10.1016/0022-5096(52)90003-3 
[3] J. M. Choung and S. R. Cho: Study on true stress correction from tensile tests. Journal of Mechanical Science and Technology 22 (6) (2008) pp. 1039-1051. doi: https://doi.org/10.1007/s12206-008-0302-3

[4] A.S. Korhonen, T. Manninen, J. Larkiola: Comparison of forming and fracture limits of cold rolled high-strength austenitic stainless steels. IDDRG 2010, Graz, pp. 535-543.

[5] D. Zhemchuzhnikova, M. Lebyodkin, D. Yuzbekova, T. Lebedkina, A. Mogucheva, R. Kaibyshev: Interrelation between the Portevin Le-Chatelier effect and necking in AlMg alloys. International Journal of Plasticity November 2018, pp. 95-109. doi: https://doi.org/10.1016/j.ijplas.2018.06.012

[6] M. Tisza, G. Gál, A. Kiss, P. Z. Kovács, Zs. Lukács: Classic sheet formability tests for qualifying high strength steel sheets. Proceedings of Miskolc University, Multidisciplinary Sciences 4 (1) (2014) pp. 39-48, in Hungarian.

[7] J.A.H. Ramaekers: A criterion for local necking. Journal of Materials Processing Technology 103 (1) (2000) pp. 165-171. doi: https://doi.org/10.1016/S0924-0136(00)00410-6

[8] S. Coppieters, J.-H. Kim, K. Denys, S. Cooreman, D. Debruyne: On Complete Solutions for the Problem of Diffuse Necking in Sheet Metal. Procedia Engineering 207 (2017) pp. 2012-2017. doi: https://doi.org/10.1016/j.proeng.2017.10.1060

[9] J.-H. Kim, A. Serpantié, F. Barlat, F. Pierron, M.-G. Lee: Characterization of the post-necking strain hardening behavior using the virtual fields method. International Journal of Solids and Structures 50 (24) (2013) pp. 3829-3842. doi: https://doi.org/10.1016/j.ijsolstr.2013.07.018

[10] N. Tardif, S. Kyriakides: Determination of anisotropy and material hardening for aluminum sheet metal. International Journal of Solids and Structures 49 (2012) pp. 3496-3506.

doi: https://doi.org/10.1016/j.ijsolstr.2012.01.011

[11] V-T. Nguyen, S-J. Kwon, O-H. Kwon and Y-S. Kim: Mechanical Properties Identification of Sheet Metals by 2D-Digital Image Correlation Method.

Procedia Engineering 184 ( 2017 ) pp. 381-389.

doi: https://doi.org/10.1016/j.proeng.2017.04.108 
[12] J. Kang, D.S. Wilkinson, M. Jain, J.D. Embury, A.J. Beaudoin, S. Kim, R. Mishira, A.K. Sachdev: On the sequence of inhomogeneous deformation processes occurring during tensile deformation of strip cast AA5754. Acta Materialia 54 (2006) pp. 209-218.

doi: https://doi.org/10.1016/j.actamat.2005.08.045

[13] H. Halim, D. S. Wilkinson, M. Niewczas: The Portevin-Le Chatelier (PLC) effect and shear band formation in an AA5754 alloy. Acta Materialia 55 (2007) pp. 4151-4160.

[14] P. Hora, B. Berisha, M. Gorji, N. Manopulo: A generalized approach for the prediction of necking and rupture phenomena in the sheet metal forming. IDDRG Conference 2012, Mumbai, India.

URL https://www.researchgate.net/publication/269709664

[15] M. Merklein, A. Kuppert, M. Geiger: Time dependent determination of forming limit diagrams. CIRP Annals - Manufacturing Technology 59 (1) (2010) pp. 295-298.

doi: https://doi.org/10.1016/j.cirp.2010.03.001

[16] H. Friebe, T. Möller: Aktueller Stand der zeitabhängigen Verfahren.

Presentation des Arbeitskreises NAKAJIMA, Stand 28.02.2012, Düsseldorf. GOM documenation.

URL https://www.gom.com/ 